\title{
ORGANIZATIONAL LEARNING AND DIVERSIFICATION
}

\author{
JOHANNES M. PENNINGS \\ University of Pennsylvania \\ HARRY BARKEMA \\ SYTSE DOUMA \\ Tilburg University
}

\begin{abstract}
Employing concepts of lateral and longitudinal learning, we examined the dissolution of 462 expansions of Dutch firms, both acquisitions and new ventures. We interpreted the endurance of an expansion as reflecting success. Results show that expansions were more persistent when related to a firm's core skills, fully owned, and the result of acquisition rather than internal development. Expansions were also likely to last longer if a firm's prior diversification activity level was high.
\end{abstract}

This article presents an empirical study on organizational learning and corporate diversification. The primary research question links these concepts and explores whether expansion decisions are better if they are anchored in organizational know-how. Are expansion projects more successful if they are proximate to firms' core skills, and do diversifying firms gain from experiences with earlier diversification moves?

Diversification decisions are among the most important a firm's managers make. Diversification extends a firm's domain but entails risk and uncertainty. Firms seek to bridge the distance between their current stock of know-how and that which they aspire to hold. Internal development, including innovation, amounts to the bridging of that distance into the future (Pennings \& Harianto, 1992), and acquisitive activities can be viewed as lateral bridging, linking proprietary know-how and the expertise of target firms (cf. Pitts, 1977). Expansions extend a firm's products, markets, technologies, and other resources.

Learning is pertinent in that expansion projects vary in their closeness to current organizational cognitions and experiences. Their degrees of prox-

We acknowledge the research assistance of Michael Schellekens and Kyungmook Lee, the statistical advice of Goetz Rohwer, and the comments of Terry Amburgey, Edward Bowman, Josef Bruderl, Sea-Jin Chang, Daniel Levinthal, Arjen van Witteloostuijn, and two anonymous referees. Errors remain our responsibility. Financial support for the study was furnished by the Wurster Center for International Management Studies at the Wharton School of the University of Pennsylvania. 
imity can be inferred from traditional attributes of diversification, including direction, mode, location, and ownership. Expansion projects will be more certain and familiar if they involve related diversification and existing organizations, they take place domestically, and are wholly or majority owned. Learning can also be placed in a multiperiod context by stipulating that corporate expansions will add to a firm's cognitions and experiences. The more a firm has accumulated diversification experiences, the greater is the likelihood that a new project is a suitable extension of the firm's boundaries. Learning is a useful concept in a theory of diversification because both laterally and longitudinally, expansions are beneficial if they are relatively proximate to a firm's current skills.

A large body of literature already exists on the relative benefits of various diversification strategies, with the dominant theme being that diversifiers perform better if their ventures are attached in core competencies (Bettis \& Hall, 1982; Hoskisson \& Hitt, 1990; Montgomery, 1985; Palepu, 1985; Rumelt, 1974; Varadarajan \& Ramanujam, 1987). Much of this literature has focused on lateral relatedness. A smaller number of studies have examined diversification in a dynamic context. Amburgey and Miner (1992), for example, examined longitudinal relatedness in diversification, whereby a firm is more likely to repeat a type of diversification it has already carried out. A comprehensive review of the literature by Ramanujam and Varadarajan showed that many of the findings to date have been based on cross-sectional comparisons of diversified firms. They advocated a departure from current practice and stressed the "need to shift the focus of analysis from overall profiles of firm diversity to individual diversification projects and cumulative diversification experiences" (1989: 539). That is, there is a need for research that (1) examines individual expansion projects and (2) analyzes what managers have learned from those projects.

\section{BACKGROUND AND HYPOTHESES}

Diversification is a central concept in the field of strategic management. Organizations have displayed a wide range of behaviors intended to extend the boundaries of their competencies. Many reasons motivate expansions, including the transfer of a firm's know-how, enhancement of its scale economies, growth in market power, and spreading of risk.

Conceptualizing a firm's expansions as a matter of organizational learning suggests a framework in which corporate cognitions limit the sort of actions conceivable. Organizations evolve as they accumulate experiences, incrementally adjusting their reactions to similar problems while absorbing feedback about past decisions. Inasmuch as expansions represent a homogeneous class of diversification decisions, they are manifest in complex and diverse ways. An expansion that follows a firm's trajectory of decisions is likely to reflect a plethora of prior decisions that its managers have been involved in. Experiences with certain expansions should therefore impart a greater capacity to implement subsequent expansions. 
Expansions are more likely to succeed if they are similar and related to what a firm has done before. Repeated behavior by a firm confers competency, as such authors as Williamson (1977) and Nelson and Winter (1982) have suggested. The Nelson and Winter study is particularly important because it stipulates a model of organizational learning.

Learning has become a prominent concept in organization theory and strategic management, but divergent approaches prevail. Nelson and Winter (1982) represented an economic view, mixed with psychological concepts such as "scripts," which refer to managerial dispositions that affect perceptions and limit the sort of actions available to managers. This approach complements the large body of work by March and his colleagues. March's (e.g., March, 1988; March, Sproull, \& Tamuz, 1991) views on organizational learning are complex and anchored in qualitative research. The link between outcomes and managers' evaluations of those outcomes is often tenuous. Organizations attend to multiple validations of events, decisions, and underlying aspirations. Significant experiences with corporate expansions would depend as much on organizational aspirations as on the actual unfolding of events.

The March position embodies a near phenomenological view and mirrors a strong psychological orientation. Such a position is rich and contrasts rather sharply with the "scanty theory of learning" (Van Witteloostuijn 1990: 184) in economics. The scanty theory seems difficult to link with the more analytical, linear, and comparative approach of economists like Nelson and Winter (1982) and other recent analysts of organizational learning (cf. Carley, 1992; Huber, 1991; Levinthal \& Cohen, 1990). Yet the qualitative and quantitative approaches have important implications for strategic decision making in general and diversification moves in particular. Although we followed a comparative research strategy, qualitative inroads are desirable and feasible and will be suggested at appropriate locations in this article.

Nelson and Winter's (1982) contribution exhibits an incremental view of diversification. Whether through acquisition or innovation, firms are inclined to stay in the vicinity of their competencies. Discontinuous expansions are surrounded with more risk and are bound to have higher failure rates. Authors writing on the various aspects of diversification appear to share this view. For example, there is little evidence of unrelated acquisitions (Montgomery, 1979) or radical innovations (Pennings \& Harianto, 1992) faring well. Kazanjian and Drazin (1987) elaborated on the issue of distance between proprietary and external know-how in their attempt to explain diversification failures.

\section{Diversification Relatedness}

Porter (1987) addressed the question of relatedness and performance on the project level. He found that firms divested a very large proportion $(60 \%)$ of corporate acquisitions involving industries unrelated to their own. The 
implication is that acquired firms and their markets, products, technologies, and other specialized resources are difficult to integrate with an acquirer whose own skills diverge from those of the acquisition or lack potential synergy with them. But relatedness is not without costs. Jones and Hill (1988), for example, suggested that the cost of administrating related acquisitions is significantly higher than the cost of administrating unrelated ones. Such costs might trigger divestments (cf. Ravenscraft \& Scherer, 1991).

Relatedness, as Rumelt (1982) showed, is manifested in many different ways. Firms can extend their strategic domains horizontally or vertically. Authors have distinguished between horizontal, related, and unrelated diversification. These distinctions correspond to varying degrees of an expansion's cognitive distance from a firm's base, with horizontal being more proximate than related, and related more proximate than unrelated. Horizontal expansions are expected to be more successful than unrelated ones simply because they involve projects in the diversifying firm's industry. Horizontal expansions at the three- or four-digit Standard Industrial Classification (SIC) code level confer greater familiarity than those at the two-digit level, since the former reside in the vicinity of a firm's core skills. They also engender enhanced economies of scale. Horizontally related expansions are also more likely to succeed than unrelated ones because of economics of scope. Such economics arise when two products or services share the use of a common production factor.

Vertical relatedness is more problematic. Rumelt (1974) found that vertically integrated firms were among the worst performers. In later research (1982), however, he found that inferior performance might be industryspecific and that if industry differences were held constant, the performance of vertically integrated firms did not differ from the average performance in their industry. Rumelt did not provide a theoretical basis for his finding, but the above-mentioned learning theory suggests a plausible extension.

We expected vertical expansions to be more successful than unrelated expansions for a variety of reasons. First, managers tend to be much more familiar with supplier and customer industries in a vertical expansion than in an unrelated expansion. For this reason alone, fewer mistakes in making diversification decisions are expected. Second, the development and introduction of radically new products may require specific investments in several stages of production and distribution. Synchronization of such investment decisions may be easier to achieve within one firm or with partners with which a firm is well acquainted.

Synchronization is essentially a transaction cost argument, but it can be supplemented with the present familiarity argument. Whenever transactions depend on specific investments, vertical integration will be beneficial (Williamson, 1977, 1985). If the rate of innovation increases, the need for specific investments also increases. To the extent that managers are able to identify situations with increasing asset specificity, vertical expansions will be beneficial. Vertical technological interdependence also augments familiarity, and firms show a high propensity toward close interfirm ties. For 
example, research on the automobile industry by Clark and Fujimoto (1991) revealed that vertically interdependent firms form dense social networks and enduring, cooperative supplier arrangements. Such supplier arrangements are likely to diffuse information vertically and result in spillover of intangible assets among the firms involved.

Hypothesis 1: Horizontal, related, and vertical expansions are more likely to succeed than unrelated expansions.

\section{Location of Expansion: Global Relatedness}

Relatedness can also vary with respect to the location of expansion projects, and geographical dispersion has in fact been proposed as an alternative strategy for risk dispersion (Kim, Hwang, \& Burgers, 1989). Buhner (1987), for example, argued that firms might opt for foreign expansion when domestic horizontal and vertical diversification are no longer feasible.

Kogut and Singh (1988) partly corroborated this view, finding that large industrial firms preferred "greenfield operations," or newly created establishments. Their study also made another point concerning relatedness and learning: Barriers to foreign entry need not be exclusively economic, but can also be social. In fact, the greater the cultural distance between two countries, the less likely is a firm from one country to expand single-handedly into the other. Firms that expand globally will encounter different customs, traditions, and beliefs about management.

The issue is highly complex, however. Interactions between location and mode of expansion are possible. Apart from national culture, other dimensions render foreign expansion more hazardous than domestic expansion. Differences in economic development, regulatory traditions, political infrastructure, and memberships in economic blocks all may increase the riskiness of foreign expansion (Pennings, 1994). Therefore,

Hypothesis 2: Dómestic expansions are more likely to succeed than foreign ones.

\section{Mode of Expansion: Acquisition Versus Innovation}

The form in which expansion projects are implemented is a third attribute that defines the appropriateness of diversification. Takeovers and new ventures are profoundly different diversification alternatives, and those differences have triggered a great deal of interest and controversy. Porter (1987) and Hitt and his colleagues (Hitt, Hoskisson, \& Harrison, 1991; Hitt, Hoskisson, Ireland, \& Harrison, 1991a, 1991b) have pointed to some of the advantages start-ups have over acquisitions.

Porter (1987) has been a rather vocal critic of expansion through acquisition, stating that firms build up their competencies through internal development, slowly and incrementally extending their domains. Homegrown expansion is embedded in the accumulated skills of a firm, but acquired 
expansion expends major resources for the sake of subsequent amalgamation with the acquired firm's stock of know-how. Unlike acquisitive diversifiers, who seek to shortcut the slow and stepwise advancement of that stock, internal diversifiers follow a process of "logical incrementalism" (Quinn, 1980). The implication is that start-ups should be compatible with their present firms. Porter's research is rather descriptive and anecdotal, but the recent work by Hitt and his colleagues cited above and research from population ecology (e.g., Bruderl, Preisendorfer, \& Ziegler, 1992) hint that the factorings accounting for spillover are rather complex.

It could be suggested that acquisitions and start-ups represent alternative instruments of diversification. It would be consistent with the learning framework proposed here for firms to prefer acquisitions, which entail fewer risks than start-ups. Further, attachment to a long-term, acquisitive stance might strengthen a diminished propensity to internal development. Hitt, Hoskisson, and Ireland (1990) implied that a wish for such strengthening is one of the reasons managers make acquisitions rather than invest in innovation. They opt for familiar, less risky alternatives. But such conduct prevents a firm from building up unique proprietary skills that endow it with a continued advantage. In related work, Hitt and his colleagues (Hitt et al., 1991; Hitt et al., 1991a) pointed out that dwindling investments in R\&D reduce a firm's long-term competitiveness.

The issue is whether firms are able to gain enough first-mover advantages through successful new ventures to offset losses on unsuccessful new ventures. Existing firms and their business units, as targets of acquisition, have moved beyond the "liability of newness" stage (Stinchcombe, 1965). Fewer acquisitions will fail than will internally developed new ventures, but acquiring firms have to pay a price for such lower risk: acquisitions come with a premium. Other research (e.g., Hitt et al., 1991b) suggests that internally developed new ventures, when successful, will contribute much more than acquisitions to the competitive advantage and value of a firm. In fact, most empirical studies published in the finance literature have shown that acquiring firms' shareholders lose, or at least do not gain Uarrell, Brickley, \& Netter, 1988; Jensen, 1986).

Research from the population ecology tradition echoes these observations. Freeman (1990), for example, found that the mortality rate of internal corporate ventures was considerably lower than that of independent ventures. It would be interesting to know the fates of certain new ventures that Freeman classified as dead when they were acquired by other firms; they may in fact still be alive. In this study, we did not classify acquired firms or business units as failures or deaths. It is also worth mentioning that Bruderl, Preisendorfer, and Ziegler (1992) found "follower" businesses to have better survival chances than newcomers. They attributed this finding to differences in human capital, which may be lower in new firms. Obviously, start-ups triggered by an existing firm can exploit economies of scope and scale, particularly if the start-up is somewhat related to the core skills of the firm.

However, regardless of the other expansion attributes, the odds of sur- 
vival for new ventures should be relatively dismal. Start-ups entail a considerable degree of risk because of the liability of newness. They start at the beginning of the learning curve. Although firms can use their homegrown skills as a form of leverage when setting up a new venture, they face large hurdles before a venture has solidified its position. On the basis of this cursory review of the literature, we hypothesized

Hypothesis 3: Acquisitions of business units or firms are more likely to succeed than new ventures.

\section{Ownership of Expansion: Alone or with Strategic Partners}

Organizations can undertake expansion alone or share ownership with strategic partners. With the decline of merger activity and the rise of joint venturing in the 1990s, there is considerable interest in the motivations and consequences of divided ownership and control. Shared equity and control has diffused widely and appears to be a common arrangement for organizations to increase the realms of their businesses. The contributions of multiple partners are not without difficulties, however. Joint ventures entail hybrid forms of structure, staffing, accounting, and payouts (Powell, 1990), challenging organizations that experiment with interfirm relationships. Firms accumulate relationship-specific assets, which may lead to increased commitments. The persistence of alliances is the result of mutual familiarization among the partners involved. Yet diversification with partners engenders more unfamiliarity than solitary diversification. Lateral learning is indicated by the extent of ownership in that fully owned ventures are more proximate to a firm's purview than are partially owned projects.

Two views on shared ownership prevail; they could be labeled the "agency" and "strife" views. That jointly owned expansion projects present agency problems was already pointed out by Demsetz and Lehn, who argued that "in a very diffusely owned firm, the divergence between costs and benefits would be much larger for the typical owner, and he can be expected to respond by neglecting some tasks of ownership" (1990: 203). Their interpretation is applicable to concentrated ownership, ownership of large blocks, and joint ventures. For the present study, the implication is that full owners of ventures and majority owners, such as large holders of stock in publicly traded firms, are more strongly motivated to monitor and control their venture's strategic conduct than owners of more diffusely owned ventures.

The view of joint ownership as strife can be discerned in the work of Kogut (1988). Partners often face discord that was not anticipated at the onset of their alliance. Mechanisms for resolving dissension might be absent or inadequate. Conflicts and subsequent uncertainty might be most severe in the case of equal ownership, in which neither of two partners can readily prevail. The added uncertainty of incomplete control and ambiguity render partly owned expansions risky. 
As it appeared evident that ownership structure does not have a monotonic relationship with diversification outcomes, our empirical tests required further refinements. Fully owned ventures involve less risk than partially owned ventures. The magnitude of agency problems is proportional to the extent of ownership claims. Conflict and power issues are most salient when strategic partners maintain equal equity. The following general hypothesis was tested:

Hypothesis 4: Fully and majority-owned expansion projects are more likely to succeed than equally and nonmajority-owned expansion projects.

\section{Interactive Effects}

The variables linked with the four hypotheses should not be seen in isolation but rather ought to be examined for interactive relationships with expansion activities. Certain combinations of the four diversification attributes can minimize the cognitive distance between a current and desirable strategic position. Jointly owned related expansions will fare less well than those that are fully owned. Start-ups that are horizontal or vertical will fare better than those that are unrelated. A positive state of all four attributes combined describes the expansion projects with the lowest risk.

Gains from overcoming market failures (Williamson, 1977) abroad should be considerable for firms that initiate greenfield operations, which afford new opportunities to exploit firm-specific assets. These gains should be less for domestic start-ups, in which a firm is already exploiting its economies of scope. It is therefore interesting to examine the interaction effects by isolating the duration of foreign start-ups. Interaction effects might be more appropriate explanations of success than the main effects of either the mode or location variables alone. The main effects may be negative, since both foreign and start-up ventures are likely to suffer from high uncertainty and unfamiliarity. Foreign start-ups are often sales and distribution offices that introduce a diversifying firm's products in offshore markets.

Offshore acquisitions not only require a firm to familiarize itself with an alien national culture - a process that might be described as acculturationbut also require the firm to become acquainted with an alien organizational culture, that of its target firm. Such double acculturation does not occur with foreign start-ups, where the acculturation is limited to the host country's culture. Such considerations do not nullify the second and third hypothesis. Rather, these observations suggest that in the case of foreign start-ups, the nonfamiliarity argument is weaker than it would be on the basis of the main effects, of mode and location, alone.

These considerations illustrate that strategic decisions about the mode and location of expansion are interrelated and extend previous research on relatedness and mode (Ravenscraft \& Scherer, 1991; Simmonds, 1990) and on location and mode (Geringer, Beamish, \& daCosta, 1989). Of course, numerous other interactions could be added. For example, the rate of demise of 
horizontal foreign start-up ventures that are minority-owned could be investigated. Two-, three-, and even four-way interaction terms are theoretically feasible but not practical methodologically. Furthermore, the above theoretical reflections suggest that some variables might attenuate rather than amplify outcomes. Perhaps these offsetting effects might explain the inconclusive results of Simmonds (1990), who contrary to his prediction, discovered that the performance of start-ups was superior to that of acquisitions.

\section{Expansion Experiences}

This review needs to be supplemented by a brief reference to the expansion experiences that firms accumulate in the course of time. Earlier, we pointed out that firms will succeed in venturing outside the realm of their core skills if the distance between the firm and the expansion is comparatively small or incremental. This study also examined longitudinal learning as an aspect of diversification, answering the plea of Ramanujam and Varadarajan (1989), by stipulating that firms with successful track records in regard to expansions are more likely to be successful in the future. Although this prediction has been borne out in research on innovation (e.g., Pennings \& Harianto, 1992), it has not been tested for diversification in general.

Learning is manifested in two ways. The stated hypotheses pertain to the content of a firm's core skills and the degree to which new expansions have an affinity to that content. The more remote a particular expansion, the more shallow is the firm's ability to manage it. Learning can also be gained temporally, from a firm's cumulative experiences, or the process of doing (cf. Pennings \& Harianto, 1992; Rosenberg, 1987). In this study, we viewed the stream of a firm's diversification decisions as endowing it with cumulative skills. Expansions will face a better fate if the firm has been a successful diversifier before, or if it has had a strong proclivity to expand. During the merger and acquisition wave of the 1970 s and 1980 s, most firms probably participated in the economy-wide increase in merger activity, but the subsequent waves of divestment suggest that not all firms were successful in retaining their acquisitions. In fact, many firms retrenched and possibly refocused their strategies, with corresponding improvements in performance (Markides, 1992).

Over time, learning can be inferred from the prior longevity of expansion projects or simply from the magnitude of expansion activities, suggesting

Hypothesis 5: The expansion projects of firms that have successfully diversified before are more likely to succeed than the expansions of firms that have not successfully diversified.

\section{METHODS}

\section{Data}

The unit of analysis in this study was individual expansion projects. The number of projects studied was 462 . Diversification data came from 14 
large nonfinancial firms in the Netherlands over a period of 23 years, 196688. We chose this period because 1966 represents a break in Dutch merger and acquisition activity (de Jong, 1988). Before that year, merger and acquisition levels were low and stable; after 1966, there was a sharp increase. We originally defined the population of firms for study as the 20 largest (in terms of sales) nonfinancial firms in the Netherlands, a group analogous to the U.S. Fortune 500. In addition, firms had to be listed on the Amsterdam Stock Exchange. We excluded the four largest firms, Royal Dutch, Shell, Unilever, Philips Electronic Industries, and Akzo. These firms are incorporated in the Netherlands, but an overwhelming proportion of their investments and business operations take place outside the Netherlands. These firms also differ significantly from the other firms in the population in terms of the breadth of their activities, their size, and so on. For example, Royal Dutch represents almost 50 percent of the capitalization of the Amsterdam Stock Exchange. The study group left after the exclusions was fairly homogeneous, so size-related effects were unlikely to shape the outcomes of the study. We made no attempt to provide a representative survey of Dutch industry and commerce; rather, our objective was to test some hypotheses on diversification performance that should be replicated in other settings.

All expansion projects reported in the firms' annual reports were studied. For two firms, Nedlloyd and KLM, the information in the annual report was incomplete or misleading, and we decided to eliminate them from the study group. When some doubt existed about the creation or dissolution of diversification projects, we consulted Het Financiele Dagblad, the Dutch equivalent of the Wall Street Journal. In some cases, we contacted firm representatives by telephone to verify information or to eliminate ambiguity about coding. Table 1 provides descriptive statistics on 462 projects by firm, classifying the projects by the qualitative variables from which we inferred lateral learning. Table 1 also provides the firms' sales and market value for the last year of the study, 1988.

We coded all expansion data and firm-level information according to prespecified criteria and verified each others' classifications. In cases of doubt, we consulted a third researcher, but such cases were relatively infrequent. For vertical projects, some judgment was required in about 20 percent of the cases as to whether transactions between the expansion and parent firm could actually take place. The status of most of these projects could readily be coded after discussion.

For triangulation purposes, we asked an independent judge to classify a randomly selected subset of expansions. The interrater reliability between the ratings of this neutral judge and our ratings was satisfactory. Only 4 percent of the projects originally classified as vertical and 2 percent of the related projects were assigned to different categories. Moreover, the most frequent difference was that ventures initially classified as vertical were secondarily coded as unrelated. This error does not adversely affect the hypothesis testing because the error is in the direction opposite the one 


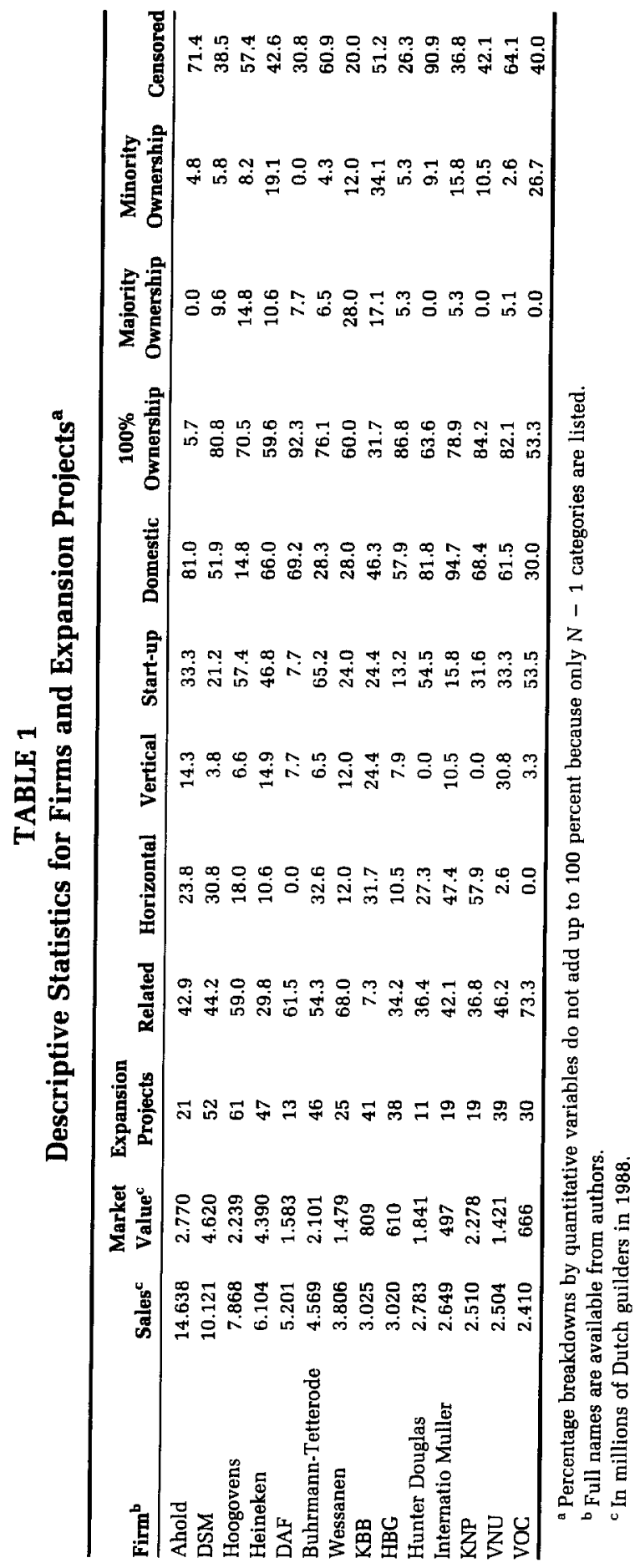


stipulated by the hypotheses, so it therefore adds credibility to the empirical tests reported here.

\section{Variables}

Diversification. Expansion projects were coded as belonging to one of the following categories: horizontally related (coded 1), used if an expansion took place within the Dutch equivalent of an SIC three-digit category; related (2), used if an expansion took place within a two-digit SIC category; unrelated (3), used if none of the other three categories applied; or vertically related (4), used if an expansion took place within a firm's value-added chain.

It is important to reiterate that our focus was on expansion projects. Thus, the diversification measure characterized relatedness between the firms and specific projects, not overall firm diversification, which often defies simple categorization based on industrial classification.

Other issues can be raised on the use of industry-classification-based diversification proxies. Simmonds (1990) resorted to an arbitrary cutoff point when imposing a diversification metric. He classified firms whose largest group of related businesses (two-digit code) accounted for 40 percent or more of their total sales as related diversifiers and those with less than $\mathbf{4 0}$ percent as unrelated diversifiers. Rumelt (1974) and Pitts (1977) employed other cutoffs. We avoided such arbitrary cutoff points in the present study.

Assignment of expansion projects to the vertical category was based on a judgment as to whether intracompany transfers of goods and services could take place, as annual reports do not give data on actual transfers. Naturally, such judgments might have added noise to the data, since not all transfers that might take place actually do materialize. Again, if the results do not confirm the hypothesis that vertical expansions are more successful than unrelated ones, the disclaimer on the measure of product diversification applies here as well.

Location. We coded an expansion as domestic (1) if it was implemented within the Netherlands and as foreign (2) if it occurred elsewhere, including in a European Union country.

Mode. We coded an expansion as an acquisition (1) if it entailed the takeover of an existing firm or a business unit and as a start-up (2) if it did not.

Our classification of ventures by mode represents another departure from current practice in strategic diversification research. Pitts (1977), Lamont and Anderson (1985), and Simmonds (1990) classified firms as externally diversified if mergers and acquisitions accounted for 10 percent or more of the change in firm sales; otherwise, they were classified as internally diversified. Such arbitrary cutoffs could be avoided in the present study, where the mode of expansion was defined unequivocally from primary sources.

Ownership. Full ownership (1) was coded if an expansion was 100 percent controlled by the diversifier. Majority ownership (2) was coded if 
the diversifier owned between 50.1 and 100 percent of the equity. Equal ownership (3) was coded if the diversifier had a 50 percent stake, and minority ownership (4) was coded if the diversifier owned less than 50 percent of the expansion's equity.

Expansion experiences. Longitudinal learning was measured as a threeyear (or five-year) moving average of previous projects' longevity, that is, a moving average that was treated as a proxy of a firm's past diversification success. For each new project, this average covered strings of three (or five) years, up to the year prior to a new expansion's onset. More formally,

$$
\frac{\sum_{j=1}^{N_{i, t-1}} \operatorname{Min} \mid \text { Age }_{i j, t-1,3} \mid}{N_{i, t-1}},
$$

where $i=$ firm, $j=$ project, and $t=$ time. $N_{i, t-1}$ is the number of firm i's projects alive at $t-1$. $^{-g_{i j, t-1}}$, is the age of projects up to $t-1$, that is, up to one time unit prior to a new expansion project. This variable was lagged to offset the overlap between this covariate and the hazard of new expansions.

The average was calculated by taking the mean duration of all projects in a three-year period over all projects initiated in that three-year period. We treated any expansion lasting more than three years as having lasted three years to accommodate the calculation of three-year moving averages. It should be pointed out that if a firm's expansion venture lasted three years, the conditional longevity was rather high. The percentage of projects dissolved was a small proportion of all projects that lasted three years or longer. A firm's track record in its diversification conduct informed us about its changing capacity to absorb and integrate a new entity into its operations. By contrast, high levels of divestment of expansion projects or restructuring activity conveyed failure to implement expansions successfully. Of course, some divestments could be interpreted as successful or beneficial, even if negative returns or even liquidation accompanied dissolution. This interpretation applied particularly to innovations and joint ventures involving acquisitions and start-ups through which the transfer of know-how had materialized. Obviously, learning does not always translate into standard accounting indicators of performance, particularly if the focus is on projects that have endowed a firm with absorptive capacity (Levinthal \& Cohen, 1990), whose future payoffs cannot readily be discerned with such indicators.

Unfortunately, the creation of learning variables as defined by a threeyear moving average confronted us with the awkward problem of left censoring. Our window of observations precluded access to diversification projects that were initiated, and possibly dissolved, before the first year of the period. We decided to use the first three years of the period to construct a baseline for each firm, although this procedure resulted in the removal of 80 observations from the data. To conduct a sensitivity analysis, we also com- 
puted a five-year average. Sensitivity analysis permits us to determine the robustness of results.

We also examined alternative measures of learning. They included percentage of surviving expansions and a measure of diversification proclivity. In the results section we dwell primarily on the earlier moving average variable but point to findings with respect to diversification proclivity, that is, levels of past expansion activity. Learning can be viewed as a firm's cumulative expansions, regardless of their outcomes. March (1988) formulated the notion of "superstitious learning," stating that a firm learns from its projects even if success cannot be assessed in terms of an objective outcome. Thus, we measured diversification proclivity as the logarithm of the number of expansions initiated up to $t-1$, regardless of outcome. The greater a firm's diversification proclivity, the better the odds of success for new expansion projects.

In addition, we considered control variables that could be interpreted as relevant to a firm's resource base and, by implication, the success of its expansions. The first control variable, profitability, was included because Jensen (1986) argued that highly profitable firms, especially those in mature businesses in which investment opportunities are limited, are likely to have extensive cash flows in excess of what is needed to fund investment projects with positive net present value. Top managers are inclined to invest such free cash in possibly unprofitable expansion projects, rather than in stock repurchases or stock dividend payouts. Similarly, we included size because large firms command more resources than small ones and therefore have a greater capacity to sustain ill-fitted acquisitions. These aspects of firms are outside the theoretical purview of this study, however. To control for conditions pertaining to firm (and, by implication, industry) differences, as well as seasonality, we added two sets of dummies. First, we included $13(\mathrm{~N}-1)$ dummy variables for all firms; second, we added three 5-year periods, 1966$70,1971-75$, and $1976-80$, with the remaining years representing the omitted category. Finally, we added the year an expansion project was initiated to various models to test the hypotheses. The period dummies can be construed as reflecting macro-economic fluctuations.

\section{Model}

The study employed a proportional hazard rate analysis, the Cox model (Allison, 1984; Rohwer, 1992), which is based on the assumption that divestment can be modeled as a logarithmic linear function of its covariates. The effects of the covariates are multiplicative because logarithmic parameters are added in a regression analysis. We chose the Cox model because of its flexibility. Unlike discrete time models, such as the log-normal and Weibull models (Allison, 1984), the Cox model does not require identification of a specific, distinct hazard function. The objective of this study was not to fit a particular rate function, but to obtain the covariates' coefficients.

The effects obtained under the Cox model indicate the relative effect of 
each covariate on the survivor function. The estimates are logarithmic likelihoods. In the regression analysis, we included both discrete variables that did not vary over time, such as types of diversification and mode of expansion, and continuous, time-varying constructs, such as learning, profitability, and sales. Proportional hazard models are quasiparametric because they rank the different durations so that the rank order of all projects represents the dependent variable. The model maximizes the proportional likelihood function that expansion project ij will be dissolved at time $t$, conditional on the hazards of other expansion projects at this time. Formally stated,

$$
\log h(t)=\frac{h_{0}(t) \exp \left[\beta_{i t} X_{i}(t)+\lambda_{i} Z_{i}(t-1)+b_{i j} B_{i j}\right]}{h_{0}(t)\left[\Sigma_{R t} \exp \left(\beta_{i t} X_{i}(t)+\lambda_{i} Z_{i}(t-1)+b_{i j} B_{i j}\right)\right]},
$$

where $h_{o}(t)$ is the baseline hazard rate at time $t, R_{t}$ is the risk set of expansion projects at time $t$, and $Z$ and $X_{i}(t)$ are time-varying covariates; $B$ does not vary over time. Unlike parametric models, such as the Weibull and log-normal, Cox models do not specify a baseline, so that any misspecification does not include bias. It is always assumed that the baseline is the same for all expansion projects, so the term $h_{o}(t)$ cancels out. The terms of the above equation are as follows:

$X_{i}(t)=$ time-varying covariates of attributes of firm $i$ at time $t$,

$X 1_{i}(t)=$ return on investment of firm $i$ at time $t$,

$X 2_{i}(t)=$ assets $(\log )$ of firm $i$ at time $t$,

$Z_{i}(t)=$ time-varying covariate of diversification of firm $i$ prior to expansion,

$Z 1_{i}(t-1)=$ cumulative duration average of expansion projects in firm $i$ at time $t-1$,

$Z 2 t_{i}(t-1)=\log$ of cumulative diversification trials of firm $i$ at time $t-1$ (alternate learning variable),

$Z_{j}(t)=$ year $t$ of project $j$ 's founding (control variable),

$B_{i j}=$ vector of categorical variables of $j$ th expansion project of firm $i$,

$B 1_{i j}=$ project $j$ of firm i's line of business,

$B 2_{i j}=$ project $j$ of firm i's mode,

$\mathrm{B}_{i j}=$ project $j$ of firm i's location,

and

$$
B 4_{i j}=\text { project } j \text { of firm i's ownership structure. }
$$

As claimed before, the duration of a venture can be construed as a measure of process. Long-enduring projects were deemed viable unless there were indications in an annual report that a venture had languished. If an expansion was dissolved after problems were reported, it was classified as a failure.

The two learning variables, the three-year moving average of expansion projects and the logarithm of the number of trials up to the year of expansion, were examined separately. We used alternative tests to further sharpen our test of organizational divestments as a function of prior experiences. 


\section{RESULTS}

All diversification activities could be classified on the basis of information that was derived from the annual reports. Tables 2 and 3 are contingency tables; they describe the categories of expansion projects in greater detail and provide information on the dependency of some of the attributes in estimating the survival of diversification. Table 4 presents the means, standard deviations, and product-moment correlations between the independent variables.

Among the total set of expansion projects, 242 were still in existence in 1988 and thus were right-censored. The remaining 220 were discontinued before that year (see Table 1). The median duration of expansion projects varied by arbitrarily defined groups. The median duration, calculated using product limit estimation functions, or life tables (SAS Institute, 1988), suggested that with location controlled, ventures lasted longer if they represented related diversification, were the result of acquisitions, or were not minority owned. For example, the median duration of new ventures is 12.6 years, and of acquisitions, 17.6 years. The three categories of related projects enjoyed an average longevity of 14.4 years, the unrelated ones, 10.3 years. These differences are significant at the 5 percent level. The findings are congruent with graphs showing survival curves. Unrelated, nonmajority owned, and newly founded ventures show steeper decay curves-or their complements display more positively sloping survival rates. Figures 1, 2, 3, and 4 show the survival curves for the four types of expansions. The horizontal axes represent years, the vertical axes, the proportions surviving. It should be noted that these plots do not show survival curves plotted with other variables held constant.

Figure 1 reveals clear differences among the four categories of related-

TABLE 2

Cross-Tabulations of Diversification Type by Mode, Location, and Ownership Structure of Expansion Projects

\begin{tabular}{|c|c|c|c|c|c|c|c|c|c|c|}
\hline \multirow[b]{2}{*}{ Variables } & \multicolumn{2}{|c|}{ Horizontal } & \multicolumn{2}{|c|}{ Related } & \multicolumn{2}{|c|}{ Unrelated } & \multicolumn{2}{|c|}{ Vertical } & \multicolumn{2}{|c|}{ Total } \\
\hline & $N$ & $\%$ & $N$ & $\%$ & $N$ & $\%$ & $N$ & $\%$ & $N$ & $\%$ \\
\hline \multicolumn{11}{|l|}{ Mode } \\
\hline New venture & 87 & 18.83 & 34 & 7.36 & 35 & 7.58 & 15 & 3.25 & 171 & 37.01 \\
\hline Acquisition & 120 & 25.97 & 62 & 13.42 & 73 & 15.80 & 36 & 7.79 & 291 & 62.99 \\
\hline \multicolumn{11}{|l|}{ Location } \\
\hline Domestic & 69 & 14.94 & 52 & 11.26 & 72 & 15.58 & 34 & 7.36 & 227 & 49.13 \\
\hline Foreign & 138 & 29.87 & 44 & 9.52 & 36 & 7.79 & 17 & 3.68 & 235 & 50.87 \\
\hline \multicolumn{11}{|l|}{ Ownership } \\
\hline Full & 151 & 32.68 & 78 & 16.88 & 62 & 13.42 & 34 & 7.36 & 325 & 70.35 \\
\hline $50.1-100 \%$ & 18 & 3.90 & 8 & 1.73 & 11 & 2.38 & 5 & 1.08 & 42 & 9.09 \\
\hline $50 \%$ & 19 & 4.11 & 4 & 0.87 & 16 & 3.46 & 2 & 0.43 & 41 & $\mathbf{8 . 8 7}$ \\
\hline$<50 \%$ & 19 & 4.11 & 6 & 1.30 & 19 & 4.11 & 10 & 2.16 & 54 & 11.69 \\
\hline Total & 207 & 44.81 & 96 & 20.78 & 108 & 23.38 & 51 & 11.04 & 462 & 100.00 \\
\hline
\end{tabular}




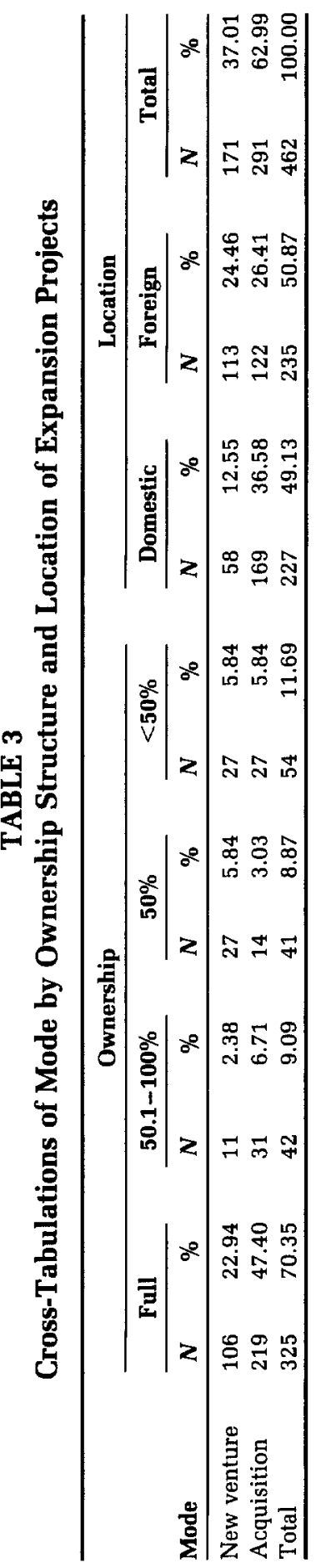




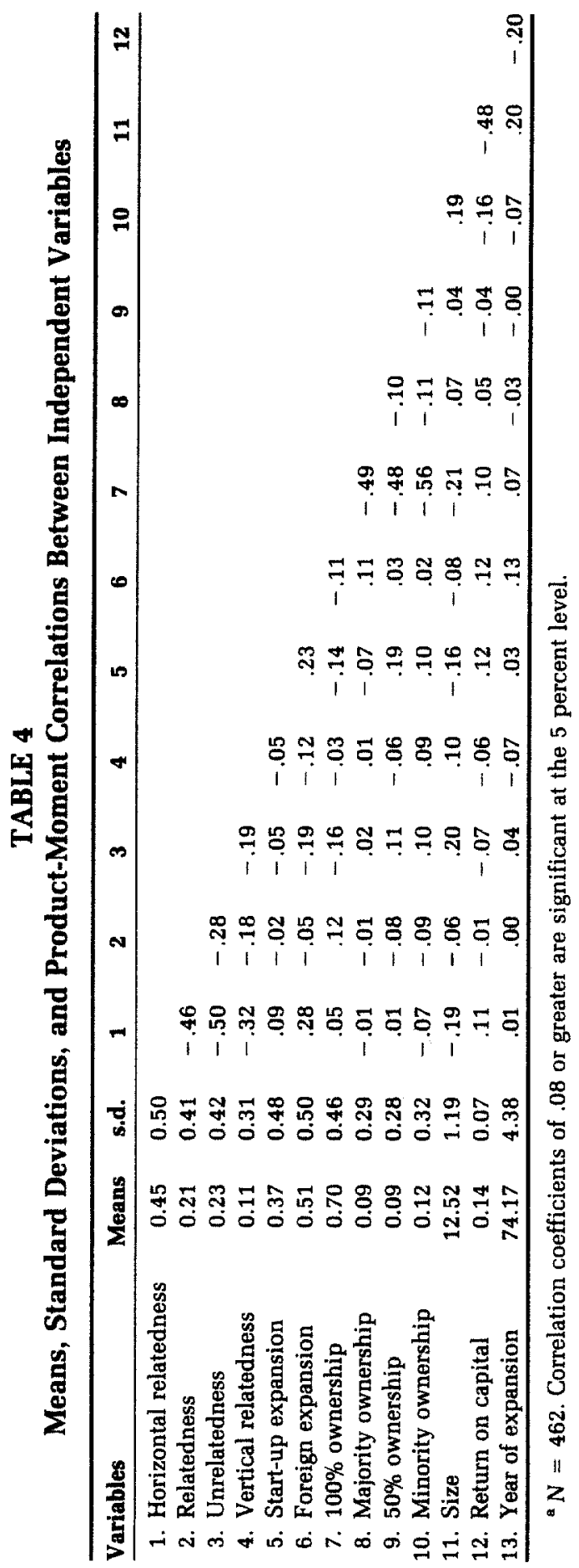


ness. Vertical expansions are by far the most persistent. The longevity of this subgroup is considerably better than that of any of the other subgroups. The unrelated expansions, as expected, were the shortest-lived and liquidated or restructured out of firms comparatively early. The other two classes, related (same two-digit code) and horizontally related (same three-digit code), occupy a middle position, less persistent than the vertical ones, but enjoying better survival rates than unrelated expansions. Although we expected a difference between the horizontal and related ventures, this graph shows them to be quite similar.

The second graph (Figure 2) contrasts the longevity of acquisitions and start-ups. The former clearly outperform the latter, although the difference is marginally significant (Mantel-Cox Statistic $=3.583, \mathrm{p}=.058$ ). The graph also shows that the superiority of acquisitions increased toward the end of our observation window.

Figure 3 provides the curves for domestic and foreign expansions. The plots for the two types show a very similar trend, and differences between them are not statistically significant.

Finally, Figure 4 shows the duration curves for expansions having different ownership structures. Projects in which a firm has exactly a 50 percent stake are the most problematic, particularly during their first 10 to 15 years. Their data compare rather unfavorably with those for the other forms of ownership, including, of course, full ownership. Their persistence is even lower than minority-owned expansions, although this latter category catches up and eventually shows a greater likelihood of liquidation. Figure 4 discloses rather clearly the superior durability of full or majority ownership; such ventures are more likely to be retained by the diversifier. The overall difference between the four curves is significant at the 5 percent level. If the 50 percent category is contrasted with the remaining ones, the difference is highly significant. In short, this last graph uncovers the significance of the ownership structures of the expansions the 14 Dutch firms were involved in.

FIGURE 1

Diversification Type

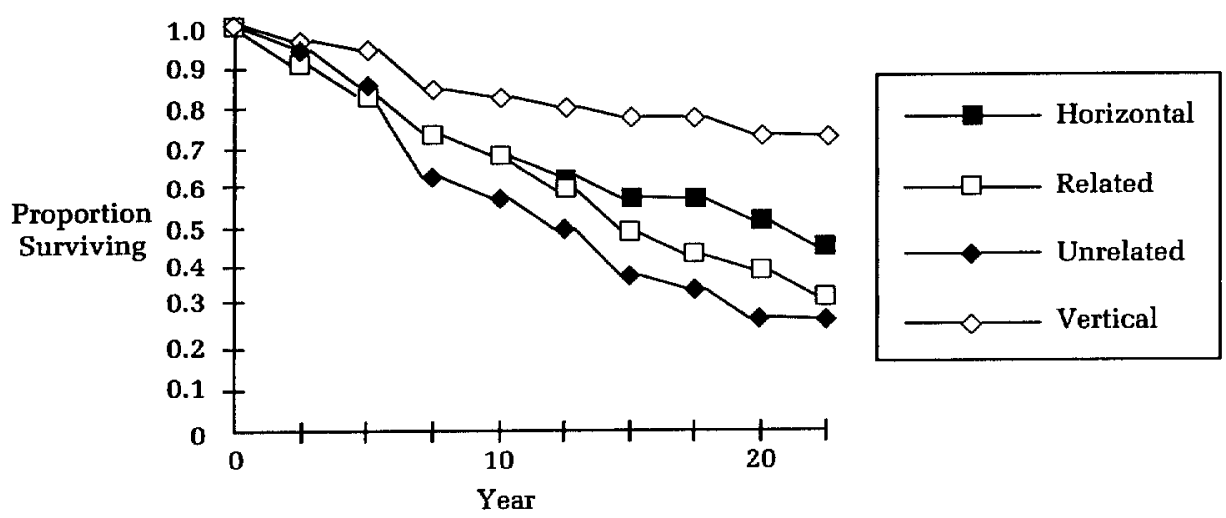


FIGURE 2

Mode

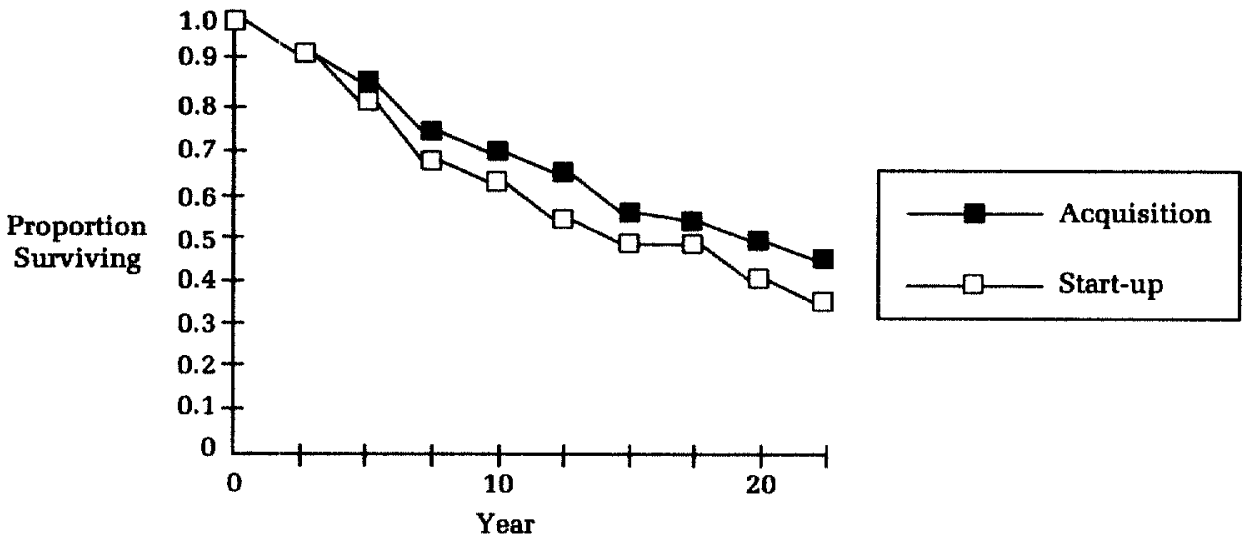

It should also be pointed out that Figure 4 shows "mortality crossover" (Vaupel \& Yashin, 1985). The survival curves of the 50 percent cohort intersect the rate for the minority cohort. The crossover signals a delayed expiration phenomenon for the former category, a feature that is somewhat analogous to the earlier mentioned liability of newness. Half-owned ventures have a higher liability than others. Conversely, minority projects enjoy a long adolescence but show higher rates of risk at later stages of their existence. Because the two ownership types intersect, their rates are not quite proportional. Later in this section, we report results on three ownership dummies and a separate estimation involving a single dummy in the $\mathbf{5 0}$ percent category.

FIGURE 3

Location

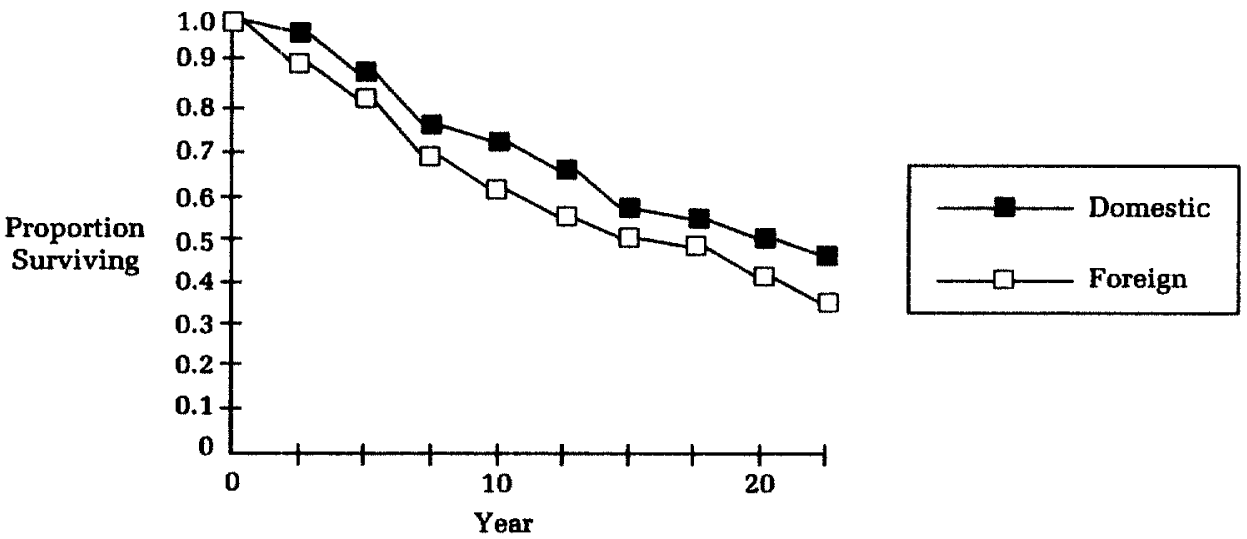




\section{FIGURE 4}

Ownership Structure

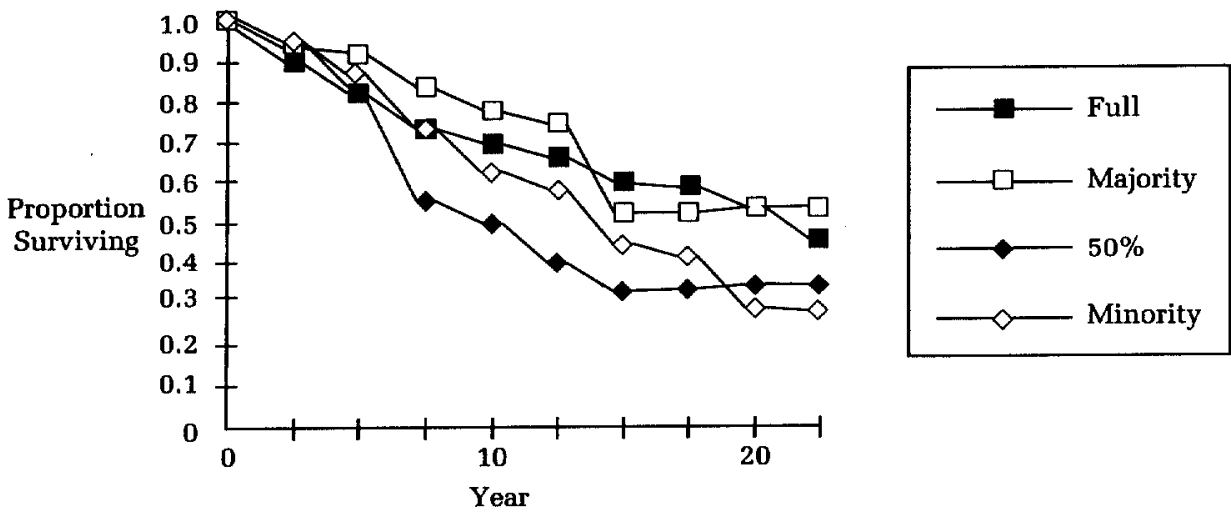

Table 5 shows the results of the proportional normal regression analyses in terms of the effects of the diversification attributes and the first learning variable, average project duration.

Vertically related projects have the best outlook. Unrelated expansions, the omitted category, are contrasted with the three related classes. The coefficients for all three dummies, horizontal, related, and vertical, are negative, signaling better survival rates then the unrelated category. The vertical relatedness category has a coefficient more than two and a half times its standard error. Hypothesis 1 is therefore strongly confirmed.

Since the dependent variable is the hazard rate, negative relatedness coefficients show that the variables have an adverse impact on the hazard rate; these results therefore imply longer duration of the expansions with high relatedness.

The results on ownership structure lend support for Hypothesis 4, which has two parts. The strife hypothesis is supported in that $\mathbf{5 0}$ percent ownership is associated with shorter life expectancies. Although the coefficient is only marginally significant (and this test is not independent of the agency-based test), some support for the strife hypothesis is indicated. Fully owned ventures have disproportionately longer durations than the other ownership categories, conforming to our agency hypothesis predictions.

The analysis was complemented with an examination of the effects of the interaction of the mode and location variables. Although all the variables might magnify each others' effects, the results presented here are for that interaction only; domestic by start-up was coded 1 and other combinations were coded 0 . When the test for interaction is included, the main effects of mode and location become significant and positive. In contrast, the interaction involving these two covariates is negative and also significant, indicat- 


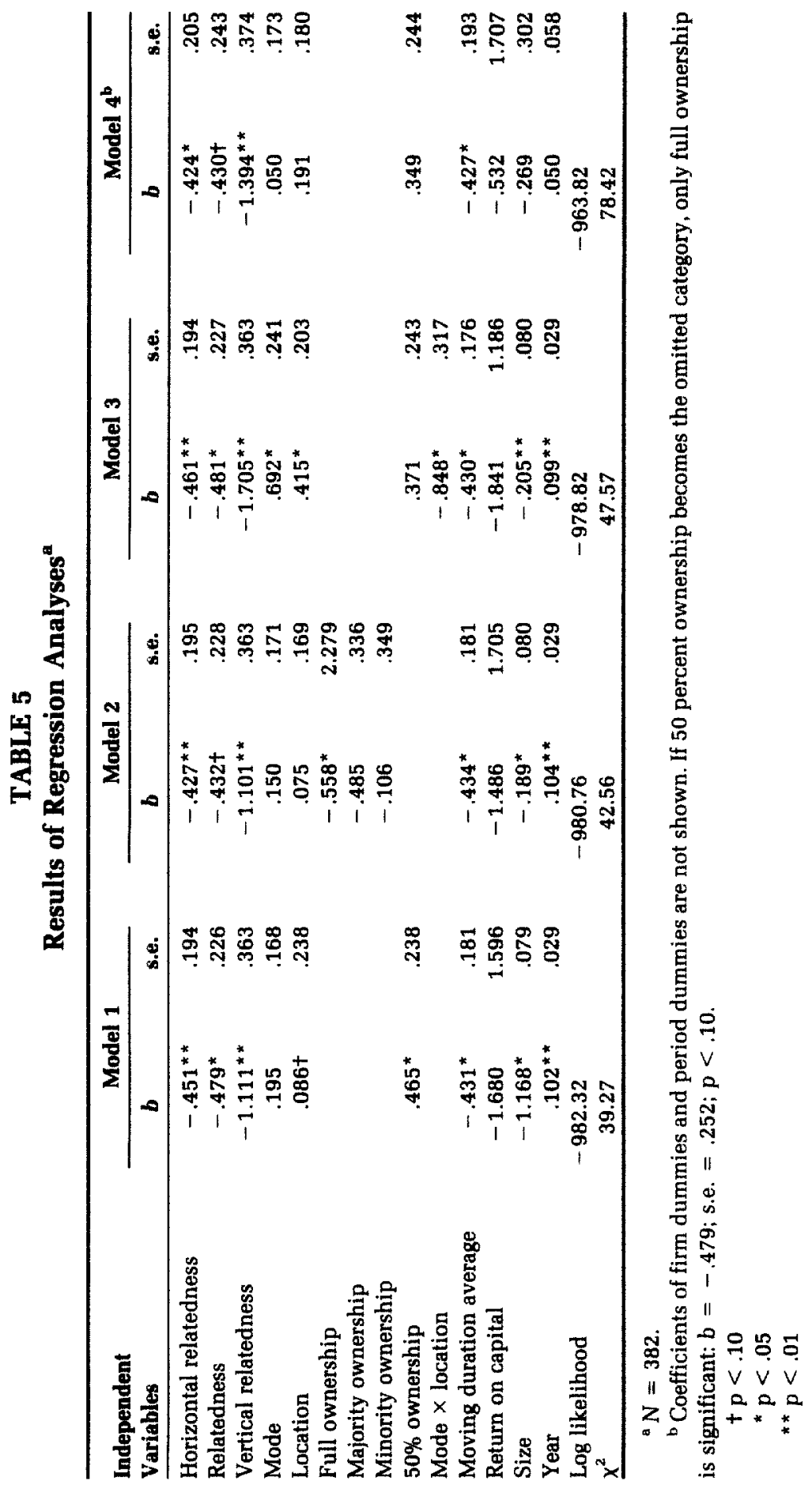


ing that foreign start-ups are more persistent than the other three classes of expansion projects.

We also tested a model that contained all five other possible interactions between the independent variables. However, all coefficients associated with these five interactions were insignificant. The increment in the chisquare statistic was also insignificant. In models 3 and 4, the addition of all the interaction terms does not lead to a significant increment in chi-square.

In summary, the results shown in Table 5 confirm the prediction regarding product diversification (Hypothesis 1) and when refashioned, the ownership prediction, Hypothesis 4 . Hypotheses 2 and 3 are also supported, although that support requires the inclusion of the mode-location interaction.

Table 5 also shows the results on longitudinal learning, as measured by the time-variant expansion experiences (the moving duration average). The effect of learning is rather strong, in the hypothesized direction, and significant at the 5 percent level across the different models. Prior positive experiences with expansion projects appears to raise the odds that new ventures will last.

Size also has strong effects. The inclusion of size, profitability, year, and their interactions in the model diminishes the effect of learning. Exclusion of size, for example, renders learning significant at the .01 level. The results remained robust when we added firm and period dummy variables to the model. Clearly, the results are congruent with Hypothesis 5, which predicts that experience is conducive to good expansion outcomes.

When we replaced the learning variable that essentially measures the idea that success breeds success with the alternate learning variable, the total number of expansions from 1966 onwards, results show significant ( $p$ $<$.10) effects for the models analogous to models 1 and 2 , but that support disappears after interaction effects and firm and period dummies are explicitly modeled. For example, although all the other coefficients are comparable to those of Table 5, the effect of the second learning variable drops from $-.183(p<.10)$ to -.180 (n.s.) as the standard error increases from .115 to .168 , based on 438 observations. ${ }^{1}$

All these results were obtained with the nonparametric, or at the most, quasi-parametric Cox model. We complemented the analysis with parametric tests requiring episode splitting ${ }^{2}$ (Rohwer, 1992), including the Weibull and log-normal models, and obtained largely the same results. Because the Cox model is more flexible in allowing time-variant covariates, we furnished the results obtained under it.

\footnotetext{
${ }^{1}$ Full results are available on request.

${ }^{2}$ Episode splitting entails the decomposition of time windows into discrete time periods, such that all observations are censored during each period, only to be re-entered in the next one. This procedure is necessary when the hazard function is assumed to have a specific distribution, such as accelerated failure time, and covariates are time variant.
} 


\section{DISCUSSION}

In this study, we sought to make a contribution to strategic diversification research through additions in theory development, level of analysis, measurement of relatedness, research design, and analytic method. The study remained, however, within the tradition of diversification research and sharpened our insights about failures of diversification.

A theory of organizational learning has been proposed in which a firm's extension of its competence is viewed as either lateral or temporal and the feedback from new ventures is seen as a basis for further development. The durability of a diversification project is inferred from a firm's successful retention of the project. To test the theory, we adopted a longitudinal research design that combined variables at the project and firm levels of analysis.

The main findings on lateral learning include the result that vertical, horizontal, and related expansion moves have the greatest chance of remaining integral parts of a firm's portfolio of business activities. Expanding firm boundaries at home rather than abroad revealed more complex relationships with a venture's survival, although its interaction with mode of expansion showed this attribute to be an important aspect. Including this interaction effect in the model also led to significant main effects associated with mode and location. The results for mode should be interpreted with care, since measurement error could be pertinent here: although acquisitions have unambiguous beginnings, start-ups can be invisible for some time before they surface in company archives and annual reports. The implications of all these comments are that expansions in general and foreign expansions in particular are a very complex phenomenon. Furthermore, given our successful efforts in moving beyond main effects, future studies should also model possible interactions among explanatory variables.

The significant interaction also suggests that intriguing aspects of diversification would not have been uncovered if the analysis had been limited to main effects alone. Not only do the main effects become significant when the interaction term is included in the model; the interaction term also points to the importance of a diversifying firm's absorbing both national and corporate cultures when it diversifies through foreign acquisitions. Foreign start-ups, such as the creation of sales and distribution offices and greenfield manufacturing operations require less learning than acquisitions. Foreign acquisitions might tax the integrative capacity of a diversifying firm beyond its limits. Barkema, Bell, and Pennings (1994) showed that foreign expansions required both the bridging of differences between native and host country cultures and some affiliation to the strategic partner, which became the diversifier's beachhead in host countries. That study employed our second index of expansion experiences, log of prior ventures, except that the learning variable was specified with respect to the class of expansions whose longevity was to be explained. The effect of longitudinal learning was strong for both foreign acquisitions and foreign joint ventures having certain own- 
ership arrangements. Learning effects are largely absent for foreign start-ups. Barkema and colleagues invoked the term "double-layered acculturation" to account for the stronger effect on diversification beyond national borders whenever diversification involves existing firms: the firm has to contend with both a foreign national culture and an unfamiliar organizational culture. Burgers, Hill, and Kim (1993) shed additional light on the complex underpinnings of foreign expansion moves in general and foreign strategic alliances in particular.

The results on longitudinal learning were also consistent with the hypothesis but were not as robust as the results on lateral learning effects. We employed two measures of lateral learning, but only the first-the moving duration average of ventures - supported the hypothesis strongly and significantly. Its effect remained when time-related controls were included. The test involving the alternate learning variable, the logarithm of the number of expansion projects, was not as strong, but this variable overlaps considerably with time. Year and size indirectly capture cumulative experiences with expansion projects over time. So it should not be surprising that results involving learning proxies are not as strong when time is explicitly modeled. A fixed-effects model like model 4 in Table 5 offers an exceedingly conservative test of the learning hypotheses because it models only withinfirm variance over time (Judge, Hull, Griffith, Lutkepohl, \& Lee, 1982). Adding period dummies further reduces the detection of potential effects of learning.

As the term intimates, longitudinal learning has a strong connection with time. Accumulation of experiences takes time. Time is a proxy for maturation, development, and growth. Including period dummies, as we did in model 4, can be construed as creating an indirect proxy for learning, one that obviously competes with this study's direct measures of longitudinal learning. Treating time as a surrogate for learning is quite common in production function studies. For example, in their study of commercial banks, Hunter and Timme (1986) took "years" as proxies for technological change, which substituted for other production factors in explaining productivity gains in commercial banks. Those authors' measure of years as technological change is actually a proxy for maturation or learning.

In fact, firm size alone, included in all the models, should diminish the effect of organizational learning. Firm size is time-variant and therefore represents a considerable chunk of organizational learning. After all, whenever a firm grows, it will have undertaken more expansions, accumulated more experiences, and thus have gone through more learning. At any rate, whether time is measured directly or indirectly, the associated occurrence of learning should be assumed. It is obvious, however, that much more research is needed before definitive conclusions on longitudinal learning about diversification can be drawn. A related article (Barkema et al., 1994) specifically examines firms' cumulative steps onto a path of learning about foreign entry modes.

To summarize, the findings of this study drive home an important point. 
Firms that diversify take some chances, but they can decrease the probability of future divestments if they do not venture too far from their own strategic domains and maintain full or majority control over their expansion ventures. The diversifying firms in this study also revealed that success breeds success if success is defined as the persistence of expansion projects: firms with track records of durable ventures are more likely to replicate their good expansion performance in the future. Divestment and restructuring do not always signal the undoing of ill-chosen ventures, but use of these euphemistic terms cannot hide the fact that the undoing of past moves is often painful and expensive and probably an acknowledgment that investments were ill-chosen. Two related issues emerge here: the meaning of learning, and divestment as a proxy for failure.

\section{Divestment and Learning}

Our analysis raises some important aspects of two issues that are not traditionally considered in the study of diversification and learning. Our main interest has been product differentiation and mode of diversification. Given that many diversification moves entail shared ownership, it becomes important to consider a firm's experience regarding strategic partnerships and joint ventures. Such partnerships are subject to major challenges of governance, equity sharing, and control. Since the flurry of merger and acquisition has subsided and in its aftermath, joint ventures have grown in popularity (Kogut, 1988), data on strategic partnerships might currently be scant, as data on acquisition conduct were in the mid-1960s (de Jong, 1988). Yet there is some evidence that firms with track records of interfirm networking are more likely to replicate that behavior than firms pursuing more solitary avenues of innovation. A similar argument applies to firms extending their boundaries across national borders. It remains an interesting but unconfirmed hypothesis that multinational enterprises with extensive across-border expansion projects can better coordinate and integrate business units in multiple countries. Researchers investigating global diversification ought to consider the success of domestic, product, and global diversification jointly.

The results of this study merit further research on the learning of strategic partnering, a rather new form of implementing diversification strategies. Ownership takes many forms, and various kinds of hybrid structures have emerged. We found that ownership structure is not monotonic with respect to the durability of ventures. Various ownership categories can be distinguished: full, majority, minority, and half. The latter category appears quite unique. Although the hazard rate of the 50-50 subgroup was worse than that of those involving other percentages, the variation among the latter should be examined more closely. To disentangle agency and strife issues, closer examination of joint ventures is necessary. Perhaps strife is more prevalent during early phases and agency problems surface during later stages. Recall that Figure 4 showed 50 percent ventures to have the steepest survival curves. In such projects, the sharing of power by strategic partners 
might be convoluted and uneasy during the early years of the partnership, but as the partners learn, they may become more adept at resolving governance conflicts. The partners might settle their post-honeymoon difficulties and coexist profitably. Levinthal and Fichman in fact suggested this interpretation when they wrote that the "persistence of interfirm relationships can be viewed as the result of a sorting process in which firms are learning about each other" (1988: 353; emphasis added). In contrast, the major owners of majority-controlled projects have control, and power-sharing and control-of-operations issues are relatively dormant. Of course, agency problems are absent in fully owned ventures, and these show the best survival prospects.

Unlike the other hypotheses, our ownership structure predictions require complementary qualitative research. Confidential data involving one firm and some of its strategic partners within a value-added chain can reveal a process of sorting out issues of mutual concern before interfirm relationships become durable. Sometimes a firm severs strategic alliance prematurely, truncating decisions that might have yielded more feedback; this condition is not uncommon when organizations venture into uncharted decision settings (March, 1988). Alliances are dissolved for a variety of reasons, including lack of trust, superstition, ambiguity, opportunism, inequity of know-how transfer, information asymmetry, and conflict about priorities. Documentation of such thick observations is largely the realm of learning scholars like March and falls outside the purview of this study.

\section{Divestment: Success and Failure?}

The longevity of expansion projects and the learning process that accompanies them was interpreted as signaling success; ventures liquidated relatively early were viewed as less successful than enduring ones. We recognize that this opinion of expansion success might provoke a good deal of controversy, even though research has shown that divestment of ill-fitting expansions, representing unrelated diversification, results in superior organizational performance (Markides, 1992) and therefore supports the contention that unsuitable expansion is not congruent with a firm's interest. Yet some might argue that expansions can be highly successful even when they are liquidated within a short period of time. For example, projects far removed from a firm's core skills might be undertaken to transfer expertise. When unrelated technologies converge, firms may be tempted to venture into distant industries - for example, telecommunication firms might enter microelectronics, and chemical firms, biotechnology. Likewise, globalization trends can trigger firms' decisions to expand offshore. Even if dissolved, such ventures endow an organization with new experiences.

Divestitures can indeed represent important sources of diversification feedback and may in fact end up creating value for a firm. In fact, although ill-fated expansions can be labeled errors, it is prudent not to commingle such errors with errors of omission. Firms can make two kinds of errors: investments that should have been made but were not, and investments that 
were made but appeared to be a poor fit. The last type of error will undoubtedly contribute to a firm's know-how, while the first type will not. Divestitures furnish information about novel areas and endow a firm with increased capacity to absorb external technology. Also, consistent with the earliermentioned work by March (e.g., March et al., 1991), learning is not confined to identifiable points of feedback such as net present value or actual dissolution, but in fact is far more continuous, haphazard, and idiosyncratic. March and colleagues would claim that even a planned but aborted acquisition can entail learning. Clearly, there is a need to complement the present study with more qualitative research seeking to uncover some of the more complex underpinnings of organizational learning. The present results revealed extensive differences in dissolution rates (see Table 1) among the 14 firms, but the reasons for those differences remain elusive. In-depth case studies of such firms and the tracking of some decision-making processes would be highly desirable. Hickson, Butler, Cray, Mallory, and Wilson (1986), who conducted field research on some 150 strategic decisions, including expansions and divestments, illustrate such an idiographic approach. Although such research was beyond the limits of the present work, it should be pursued to obtain a more complete and valid theory of strategic learning.

Success is a complex issue and can certainly be gauged with other criteria. Some might argue that hard indicators of performance, such as an investment's net present value, internal rate of return, and other financial criteria, should be available before one judges an expansion's success. Although that viewpoint is not without merit, it is important not to dismiss our measure of success in favor of other measures. An ideal research design would incorporate multiple indicators of performance, but given the state of the art, the present measure generates a great deal of insight about expansions. The current preoccupation with restructuring, retrenchment, downsizing, and other euphemisms for the undoing of strategic diversification errors suggests that the longevity of expansion projects is quite appropriate as an indicator of success.

The survival of acquisitions and start-ups probably requires further refinement as a proxy for success. Earlier, we pointed out that acquisitions entail a premium because they are comparatively nonrisky, although foreign acquisitions require more assimilation than foreign start-ups. The survival of such as expansion may, however, furnish lower returns then a successful start-up because of first-mover advantages, enhanced absorptive capacity, and the opportunity to establish competitive advantage through learning. Clearly, an undifferentiated position that all divestitures are failures can be erroneous, and it is highly misplaced as a recommendation upon which to develop strategy prescriptions for managers.

In this article, we explicitly recognized that success is a complex issue. We distinguished between assessing the performance of individual ventures in the terms of longevity and assessing the positive externality of those 
ventures in terms of longitudinal learning. A strong correlation between these two aspects was expected and uncovered in the empirical testing.

This last observation is also in accord with the work of several authors who have disclosed the complexity of corporate expansions and their dissolution (cf. Burgelman, 1991; Levinthal \& Cohen, 1990). These authors do not provide quantifiable indicators of success that might be associated with corporate ventures. Yet their conceptual discussions point to intangible manifestations of mastery that reach far beyond convenient indicators like COMPUSTAT-derived indexes.

Burgelman (1991) addressed the question of the creation of new skills. New competencies emerge whenever fledgling start-ups arise without the interference of strategic decision makers or encroachment by competing factions in an organization. He argued that variation and selection of start-ups is conducive to the successful generation of new knowledge. Studying the Intel corporation, he attributed the divestment or retention of expansion projects to the selective process that resided inside the firm. Having a variety of start-ups endows a firm with diversity and improves its flexibility in dealing with the evolving situations, such as changing technologies and newly emerging dominant designs. Levinthal and Cohen (1990) also invoked nonfinancial criteria when they developed the concept of absorptive capacity. Such capacity is difficult to operationally measure yet significant in signaling success such as adaptiveness to rapidly and unpredictably changing technological conditions. Parenthetically, both Burgelman and the present study present an interesting confrontation with population ecology. Our study has an ecological flavor in that it examines the duration of expansion projects, yet it presents findings that stress organizational learning rather than inertia. What is being selected, both here and in Burgelman's study, are projects rather than firms. Both studies develop an argument that is based on learning and flexibility rather than on inertia and rigidity.

\section{Cross-National Issues}

This study's reliance on non-U.S. data is a strength, but its unique provenance should be recognized. The sort of data employed in this study might not be appropriate for reporting diversification moves in other countries. Furthermore, the Netherlands has been a prolific player in foreign direct investments, ranking, for example, in the top two or three countries among all countries investing in the United States, even though it has a comparatively small economy. Foreign start-ups and acquisitions involving Dutch firms may therefore have lower failure rates than those involving other countries. Obviously, there is a need to develop multiple-country data.

Similar comments can be made about the role of national governments in shaping corporate strategies. In the United States, for example, many acquisitive moves would not be admissible as they violate various statutes. In the Netherlands, such regulatory constraints have been absent, although recently the European Commission has become proactive in regulating firm 
behavior, particularly if the firms involved are large and have the potential to create market power.

Finally, it is important to note that "foreign" remained largely unspecified in this study, where proximity to the Netherlands and membership in the European Union signaled higher familiarity. For European Union firms, expansion into other European Union countries will probably be more successful than expansion into, for example, Pacific Rim countries, where the differences in culture and economic regulations will create more difficulties (Pennings, 1993). Additional research specifying attributes of foreign sites is therefore desirable. Location is a multifaceted diversification attribute and requires careful measurement.

\section{Conclusion}

This study opens up some interesting new lines of research by shifting the focus from the firm level to the level of expansion moves. The concept of organizational learning can fruitfully be incorporated in a study of expansion projects examined at a project level. Such a theoretical and empirical approach will also help in overcoming the perennial problems of classifying firms and their diversification by SIC code or some other arbitrary criterion. Future research should consider the dynamic interplay of success factors over time. It is important to replicate this study on other national data archives and to incorporate research on domestic, product, and global diversification. The frontiers of knowledge are expanding, thanks to multidisciplinary inputs and advances in research methods and statistical tools. It is up to strategy researchers to push those frontiers even further. Finally, this study suggests that research driven by a learning theory can produce interesting and practical insights about corporate diversification and the causes of its success or failure.

\section{REFERENCES}

Allison, P. D. 1984. Event history analysis: Regression for longitudinal data. Beverly Hills, CA: Sage.

Amburgey, T. L., \& Miner, A. I. 1992. Strategic momentum: The effects of repetitive, positional and contextual momentum on merger activity. Strategic Management Journal, 13: 335348.

Barkema, H., Bell, J., \& Pennings, J. M. 1994. Foreign entry, cultural barriers and learning. Working paper, Department of Management, University of Pennsylvania, Philadelphia.

Bettis, R. A., \& Hall, W. K. 1982. Diversification strategy, accounting determined risk, and accounting determined return. Academy of Management Journal, 25: 244-264.

Bruderl, J., Preisendorfer, P., \& Ziegler, R. 1992. Survival chances of newly founded business organizations. American Sociological Review, 57: 227-242.

Buhner, R. 1987. Assessing international diversification of West German corporations. Strategic Management Journal, 8: 25-37.

Burgelman, R. A. 1991. Intraorganizational ecology of strategy making and organizational adaptations: Theory and field research. Organization Science, 2(3): 239-262. 
Burgers, W. P., Hill, C. W. L., \& Kim, W. C. 1993. A theory of global strategic alliances: The case of the global auto industry. Strategic Management Journal. 14: 419-432.

Carley, K. 1992. Organizational learning and personnel turnover. Organization Science, 3: $20-46$

Clark, K., \& Fujimoto, T. 1991. Product, development, performance: Strategy, organization and management in the world auto industry. Boston: Harvard Business School Press.

de Jong, H. W. 1988. De concentratie beweging in de Europese economie. Economische Statistische Berichten, 73: 224-228.

Demsetz, H., \& Lehn, K. 1990. The structure of corporate ownership: Causes and consequences. In H. Demsetz (Ed.), Ownership control and the firm: The organization of economic activity, vol. 1: 202-222. Cambridge, MA: Basil Blackwell.

Freeman, J. H. 1990. Ecological analysis of semiconductor firm mortality. In J. V. Singh (Ed.), Organizational evolution: New directions: 53-77. Newbury Park, CA: Sage.

Geringer, J. M., Beamish, P. W., \& da Costa, R. C. 1989. Diversification strategy and internationalization: Implications for MNE performance. Strategic Management Journal, 10: 109119.

Hickson, D. J., Butler, R. J., Cray, D., Mallory, G. R., \& Wilson, D. C. 1986. Top decisions. San Francisco: Jossey-Bass.

Hitt, M. A., Hoskisson, R. E., \& Ireland, R. D. 1990. Mergers and acquisitions and managerial commitment to innovation in M-form firms. Strategic Management Journal, 11: 29-47.

Hitt, M. A., Hoskisson, R. E., \& Harrison, J. S. 1991. Strategic competitiveness in the 1990s: Challenges and opportunities for U.S. executives. Academy of Management Executive, 5: 7-22.

Hitt, M. A., Hoskisson, R. E., Ireland, R. D., \& Harrison, J. S. 1991a. Effects of acquisitions on R\&D inputs and outputs. Academy of Management Journal, 34: 693-706.

Hitt, M. A., Hoskisson, R. E., Ireland, R. D., \& Harrison, J. S. 1991b. Are acquisitions a poison pill for innovation? Academy of Management Executive, 5: 22-34.

Hoskisson, R. E., \& Hitt, M. A. 1990. Antecedents and performance outcomes of diversification: A review and critique of theoretical perspective. Journal of Management, 16: 461-509.

Huber, G. P. 1991. Organizational learning: The contributing processes and the literatures. Organization Science, 2: 88-115.

Hunter, W. G., \& Timme, S. G. 1986. Technical change, organization form and the structure of bank production. Journal of Money, Credit and Banking, 10(2): 152-166.

Jarrell, G. A., Brickley, J. A., \& Netter, J. M. 1988. The market for corporate control: The empirical evidence since 1980. Journal of Economic Perspectives, 2: 49-68.

Jensen, M. C. 1986. Agency costs of free cash flow, corporate finance, and takeovers. American Economic Review, 76: 323-329.

Jones, G. R., \& Hill, C. W. L. 1988. Transaction cost analysis of strategy-structure choice. Strategic Management Journal, 9: 159-172.

Judge, G. C., Hull, C. R., Griffith, W. E., Lutkepohl, H., \& Lee, T. C. 1982. Introduction to the theory and practice of econometrics. New York: Wiley.

Kazanjian, R., \& Drazin, R. D. 1987. Implementing internal diversification. Academy of Management Review, 12: 342-354.

Kim, W. C., Hwang, P., \& Burgers, W. P. 1989. Global diversification strategy and corporate profit performance. Strategic Management Journal, 10: 45-57. 
Kogut, B. 1988. Joint ventures: Theoretical and empirical perspective. Strategic Management Journal, 9: 319-332.

Kogut, B., \& Singh, H. 1988. The effect of national culture on the choice of entry mode. Journal of International Business Studies, 19: 411-432.

Lamont, B. T., \& Anderson, C. R. 1985. Mode of corporate diversification and economic performance. Academy of Management Journal, 28: 926-934.

Levinthal, D. A., \& Cohen, W. 1990. Absorptive capacity: A new perspective on learning and innovation. Administrative Science Quarterly, 35: 128-152.

Levinthal, D. A., \& Fichman, M. 1988. Dynamics of interorganizational attachments: Auditorclient relationships. Administrative Science Quarterly, 33: 345-369.

March, J. G. 1988. Decisions and organizations. Oxford: Blackwell.

March, J. G., Sproull, L. S., \& Tamuz, M. 1991. Learning from samples of one or fewer. Organization Science, 2: 1-13.

Markides, C. C. 1992. Consequences of corporate refocusing: Ex ante evidence. Academy of Management Journal, 35: 398-412.

Montgomery, C. A. 1979. Diversification, market structure and firm performance: An extension of Rumelt's model. Unpublished doctoral dissertation. Purdue University, West Lafayette, IN.

Montgomery, C. A. 1985. Product-market diversification and market power. Academy of Management Journal, 28: 789-798.

Nelson, R. R., \& Winter, S. G. 1982. An evolutionary theory of economic change. Cambridge, MA: Bellknap/Harvard.

Palepu, K. 1985. Diversification strategy, profit performance and the entropy measure. Strategic Management Journal, 6: 239-255.

Pennings, J. M. 1994. Interfirm linkages and globalization. In P. Shrivastava, A. Huff, \& J. Dutton, Advances in strategic management, 10: 329-335. Greenwich, CT: JAI Press.

Pennings, J. M., \& Harianto, F. 1992. Technological networking and innovation implementation. Organization Science, 3: 356-382.

Pitts, R. A. 1977. Strategies and structures for diversification. Academy of Management Journal, 20: 197-208.

Porter, M. E. 1987. From competitive advantage to corporate strategy. Harvard Business Review, $65(3): 43-59$.

Powell, W. W. 1990. Neither market nor hierarchy. In L. L. Cummings \& B. M. Staw (Eds.), Research in organizational behavior, vol. 13: 295-366. Greenwich, CT: JAI Press.

Quinn, J. B. 1980. Strategies for change: Logical incrementalism. Homewood, IL: Irwin.

Ramanujam, V., \& Varadarajan, P. 1989. Research on corporate diversification: A synthesis. Strategic Management Journal, 10: 523-551.

Ravenscraft, D. T., \& Scherer, F. M. 1991. Divisional sell off: A hazard function analysis. Managerial and Decision Economics, 12(16): 429-438.

Rohwer, G. 1992. Analysis of transition data: $A$ practical introduction with TDA. Unpublished manuscript, European University Institute, Florence.

Rosenberg, N. 1987. Inside the black box: Technology and economics. Cambridge, MA: Cambridge University Press.

Rumelt, R. P. 1974. Strategy, structure and economic performance. Boston: Harvard Business School Press. 
Rumelt, R. P. 1982. Diversification strategy and profitability. Strategic Management Journal, 3: 359-369.

SAS Institute. 1988. SAS users' guide. Cary, NC: SAS Institute.

Simmonds, P. G. 1990. The combined diversification breadth and mode dimensions and the performance of large diversified firms. Strategic Management Journal, 11: 399-410.

Stinchcombe, A. L. 1965. Social structure and organizations. In J. G. March (Ed.), Handbook of organizations: 142-193. Chicago: Rand McNally.

Van Witteloostuijn, A. 1990. Learning in economic theory: A taxonomy with an application to expectation formation. Journal of Economic Psychology, 11: 183-207.

Varadarajan, P. R., \& Ramanujam, V. 1987. Diversification and performance: A reexamination using a new two-dimensional conceptualization of diversity in firms. Academy of Management Journal, 30: 380-393.

Vaupel, J. W., \& Yashin, A. I. 1985. Heterogeneity ruses: Some surprising effects of evolution on population dynamics. American Statistician, 39(3): 176-185.

Williamson, O. E. 1977. Markets and hierarchies. New York: Free Press.

Williamson, O. E. 1985. The economic institutions of capitalism: Firms, markets, relational contracting. New York: Free Press

Johannes M. Pennings is on the faculty of the Wharton School of University of Pennsylvania. He received his Ph.D. degree from the University of Michigan. His current research interests are organizational learning and innovation and cross-national issues of strategy implementation, including executive compensation.

Harry Barkema is a professor of business administration at Tilburg University, the Netherlands. He received his Ph.D. from Groningen University. His current research interests include top management compensation and corporate strategy.

Sytse Douma is a professor of strategy and organization at Tilburg University, the Netherlands. He received his Ph.D. degree from Groningen University. His research interests involve corporate governance and corporate diversification. 